\title{
The morphology of the feet of young basketball players against non-training population
}

\author{
Agnieszka Przyszlak ${ }_{\text {ABCDEFG }}$
}

${ }^{1}$ Faculty of Physical Education, University of Rzeszów

\begin{abstract}
The aim of the study was to evaluate the changes in the morphology of the feet of basketball players aged 11-18 against the non-training population.

267 people practicing basketball in sports clubs of the Podkarpackie Province were examined. The control group are girls and boys who do not practice sport, students of the Podkarpackie Province primary and secondary schools (total: 294 persons).

To assess the state of the foot a podoscope constructed by W. Sliwa [1] was used. Measurements were made on rested people before physical activity. The computer program allowed the analysis of parameters of feet set on the basis of several of its characteristic points. Based on Clark's angle the feet were qualified to one of the five groups [2]: regular feet, pronated feet, flat feet, high arch, excessive high arch.

The analysis of the types of feet showed that the most common were regular feet. Under the influence of sports training an increased incidence of adverse changes characterizing the feet of male and female players was observed. An increased occurrence of arch feet among both genders as well as excessive arch feet among the boys and flat feet among the girls was observed.
\end{abstract}

Keywords: feet of basketball players, morphology of the feet

\section{Introduction}

This article aims to show changes in the morphology of the foot as a result of training on the example of a group of basketball players aged 11-18 years.

\section{Materials and methods}

Measurement data that was used in the analysis comes from studies of children and adolescents aged 11-18 years who train basketball and living in the Podkarpackie Province. A total of 267 people (163 boys and 104 girls) were examined. The study was conducted at the turn of 2004 and 2005 in the following clubs: Stal Stalowa Wola, Siarka Tarnobrzeg, MLKS Rzeszow, UKS TKKF Siódemka Rzeszow, CWKS Resovia
Rzeszów, KS Kontra Rzeszów, Sokół Łańcut, MOSiR Przeworsk, MKS Znicz Jarosław, Polonia Przemyśl, UKS Jurajska Przemyśl, UKS Przemyśl Gimbasket, UKS Lotnik Wierzawice. The control group students represent the results of measurements of sub-Carpathian primary and secondary schools not practicing sport (a total of 294 people including 175 boys and 117 girls). Their physical activity was limited to physical education at school.

To compensate for interindividual variation to the pace of biological development of the examined individuals the children and young people were divided into subgroups based on morphological 
age. For this purpose, the data contained in the tables developed by Palczewska and Niedźwiecka [4] and the following formula [3] were used:

Morphological age $=($ age weight + body height age) / 2

Based on the progress of the development (morphological age) respondents were split into three groups (percentile 33 and 66). In this way, the observed differences in the morphology of the foot will result from training load, and not from the diversity associated with the progress in the development of biological development.

To assess the state of the foot a podoscope constructed by W. Śliwa [1] was used. The podoscope was designed as a diagnostic measuring device for quick evaluation of the construction of the foot (Fig. 1). During the measurement the examined person stood on the transparent surface of the device evenly burdening feet. Measurements were taken before physical activity.

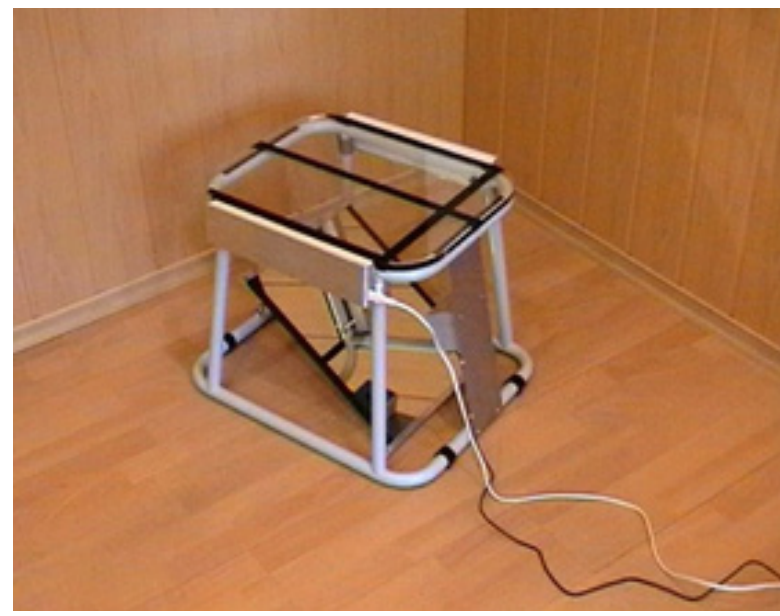

Fig. 1. The podoscope

The podoscope is equipped with a camera connected to the computer so that the measurements are recorded, analyzed and presented in any form, including print. The morphological parameters of the right foot and left foot were analyzed separately.

From the available version of ElPodo the analysis includes the following features:

foot length pte-ap (R, L);

foot width mtt-mtf (R, L); heel width (R, L);

alpha angle - hallux [0] (R, L);

beta angle - the little finger angle $[0](\mathrm{R}, \mathrm{L})$;

gamma angle - the foot angle [0] $(\mathrm{R}, \mathrm{L})$;

Clark's angle [0] (R, L).

The program also allows the assessment of the foot based on Clark's angle and qualifying it to one of five groups [4]:
A regular feet
A pronated feet
A flat feet
A high arch
A excessive high arch
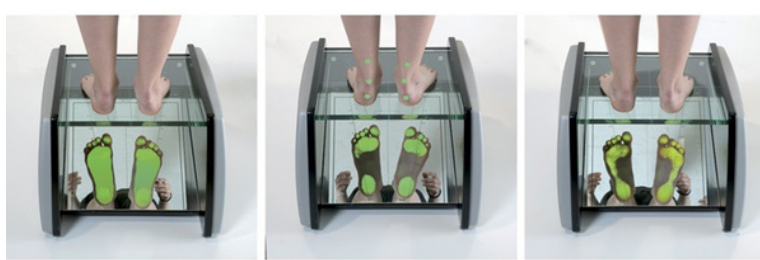

Fig.2. The image of the feet as seen by the examined person (first two photos show abnormally shaped feet, whereas the third picture is a type of foot shaped properly)

In the analysis of the collected material basic measures of descriptive statistics using Statistica for Windows were used (2007). Morphological determinants of the characteristics of the foot were assessed using Pearson product-moment correlation coefficient (r). 


\section{Results}

The development of foot features in the experimental group and the control group.

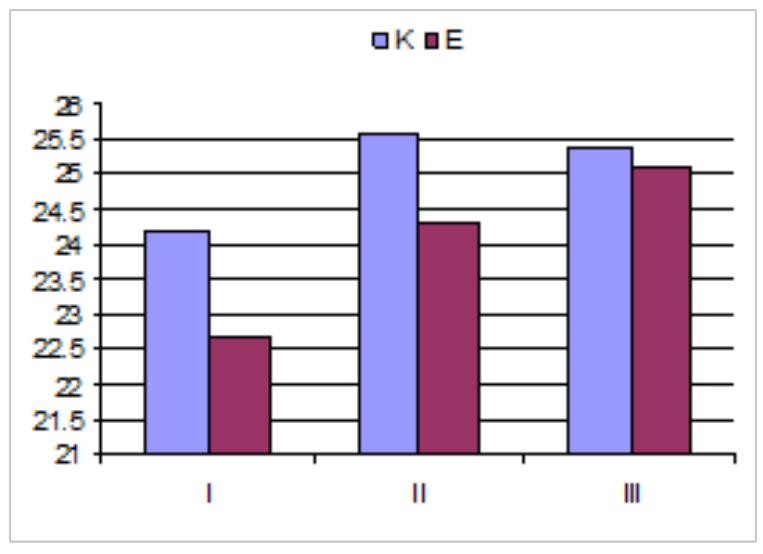

Left foot

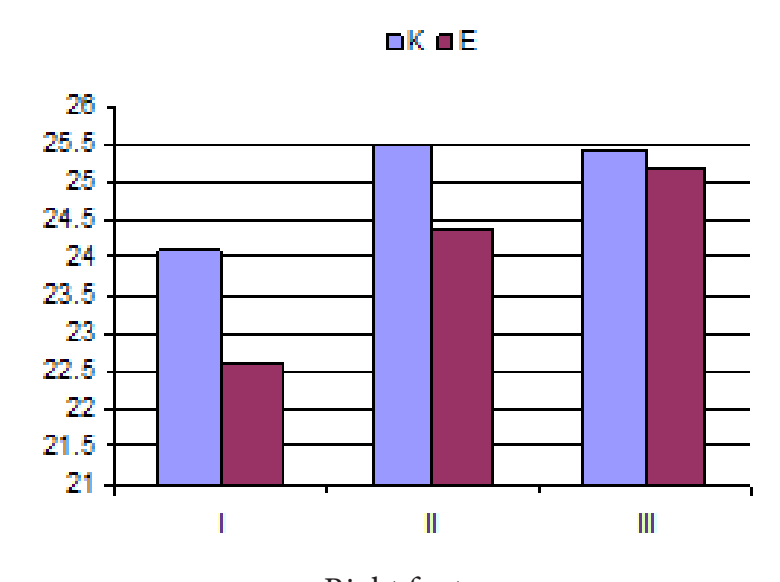

Right foot

Fig. 1. Foot length (boys)

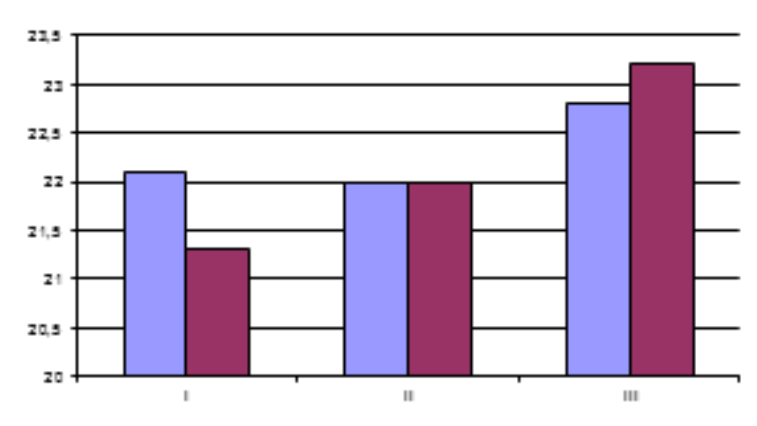

Left foot

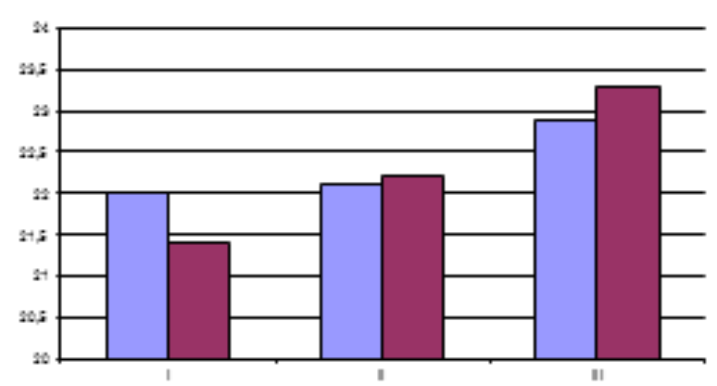

Right foot

Fig. 2. Foot length (girls)

In the analyzed period of ontogeny in case of the male and female basketball players gradual increase of the length of the right and left foot is observed. 


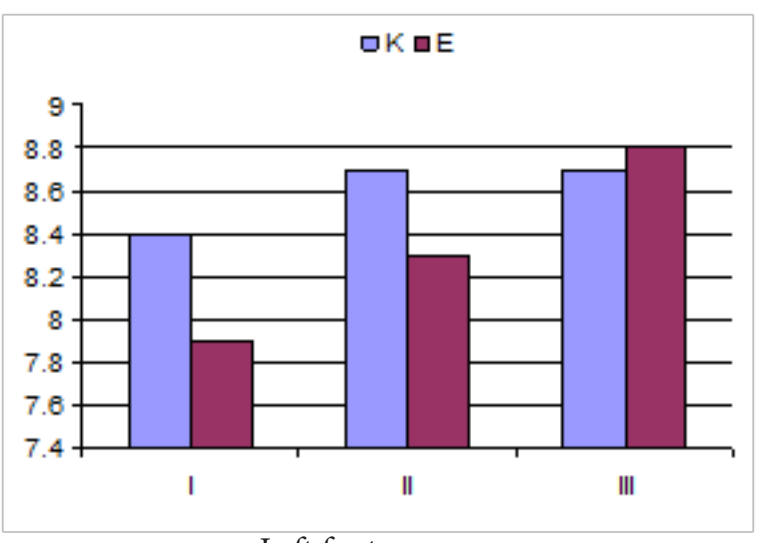

Left foot

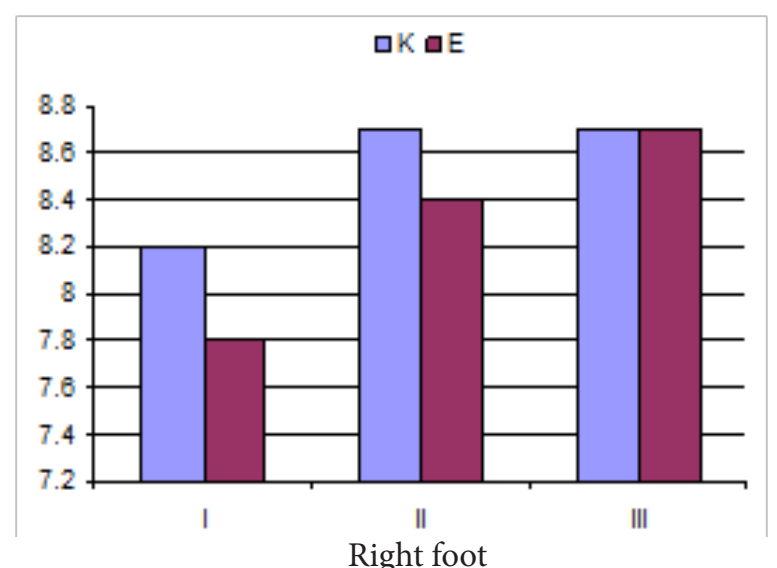

Right foot

Fig. 3. Foot width (boys)

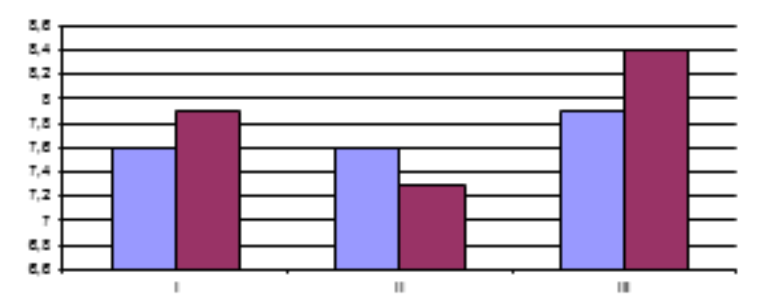

Left foot

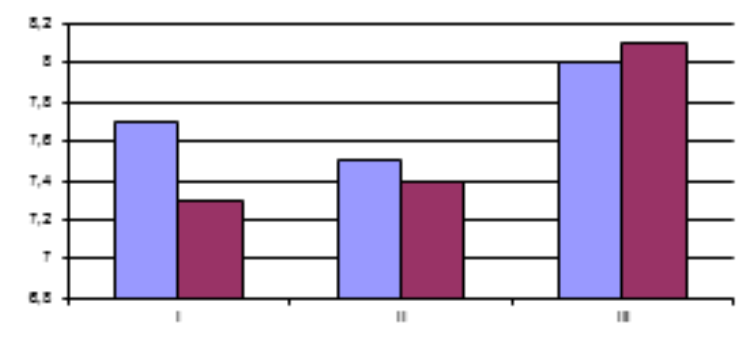

Right foot

Fig. 4. Foot width (girls)

Changes in the width of the foot are higher in case of male basketball players. In extreme age groups the width of the feet is higher in case of female basketball players.

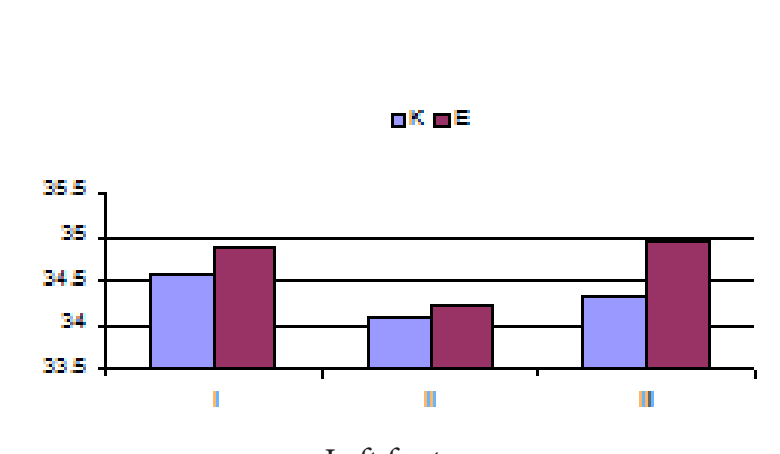

Left foot

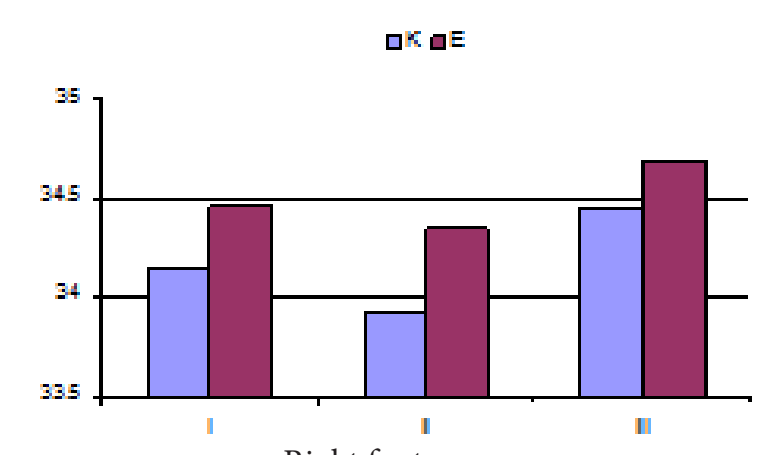

Right foot

Fig. 5. Foot index (boys) 


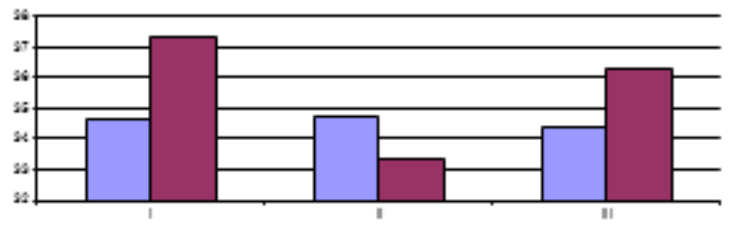

Left foot

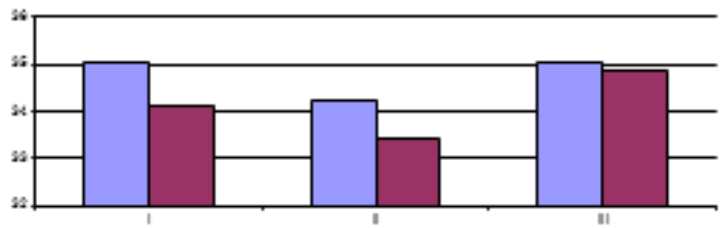

Right foot

Fig.6. Foot index (girls)

The feet of the basketball players of both genders as well as their non-training peers in each age group can be classified as narrow feet [3]. Among the oldest youth an increase in the width of the foot in relation to their length was observed again.

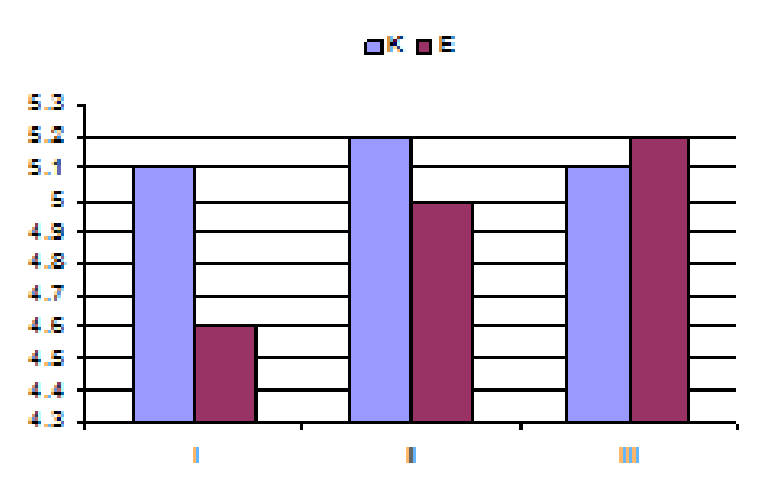

Left foot

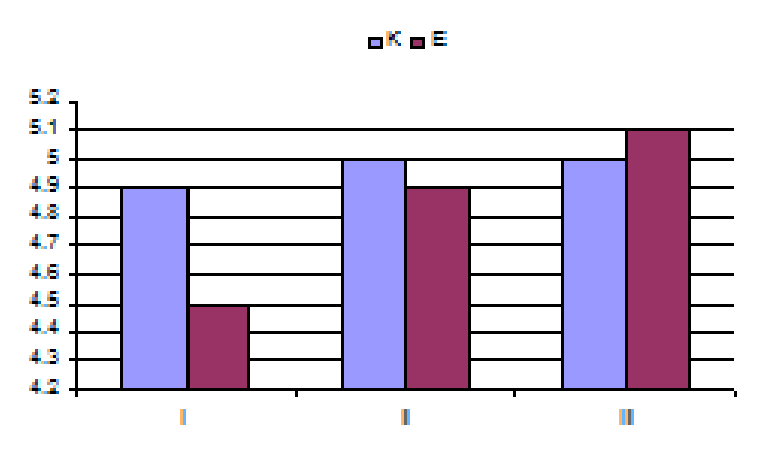

Right foot

Fig.7. Heel width (boys)

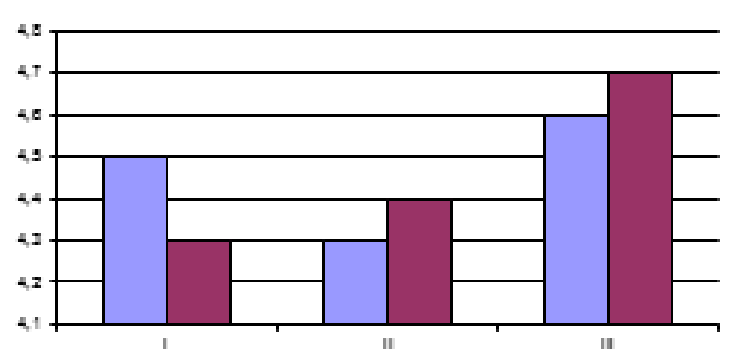

Left foot

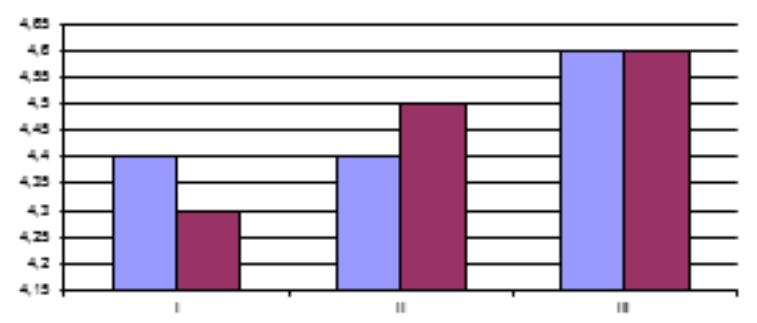

Right foot

Fig.8. Heel width (girls) 
The average values of the discussed feature in the control group of boys are at a similar level, with a gradual significant increase in the width of the heel reported among the sportspeople.

Among the youngest girls the average width of the right and left heel are higher in the control group. In the following age classes (II and III) the discussed feature presents a higher level of development among the female basketball players.

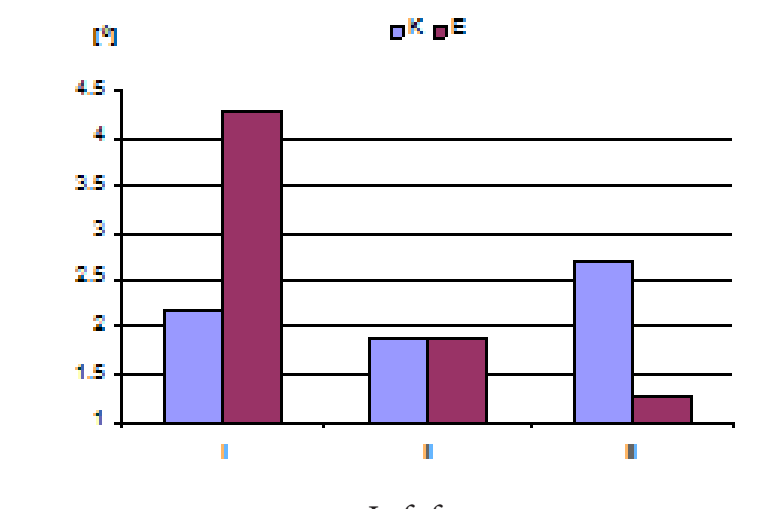

Left foot

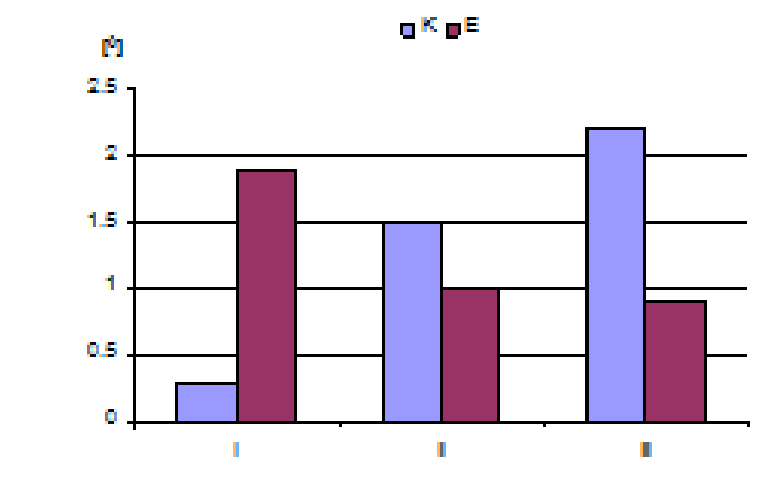

Right foot

Fig. 9. Alpha angle (boys)

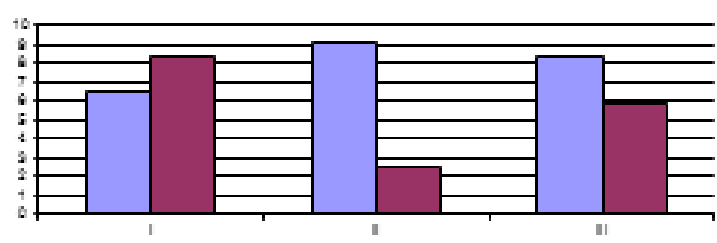

Left foot

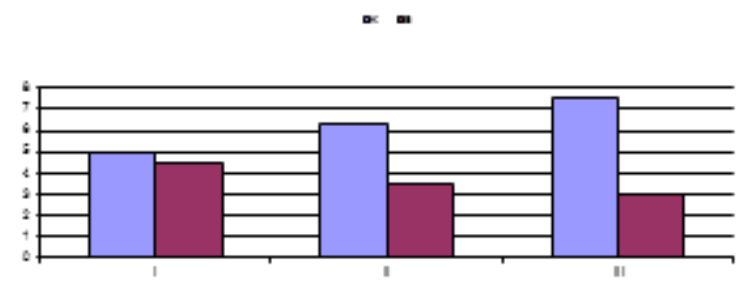

Right foot

Fig. 10. Alpha angle (girls)

The size of the analyzed foot angles exhibit poor intergroup diversity.

In all comparisons, the angle of the right foot hallux reaches higher values in the control group. Only in the youngest age group slightly increased levels of alpha angle of the left foot were recorded among basketball players. 


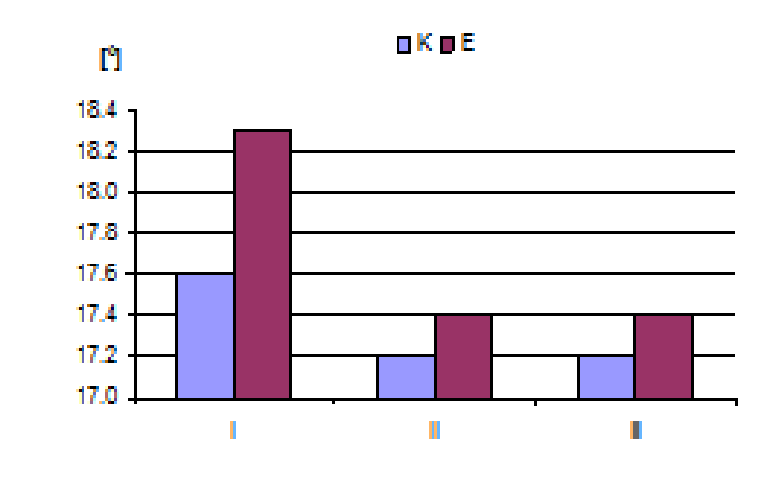

Left foot

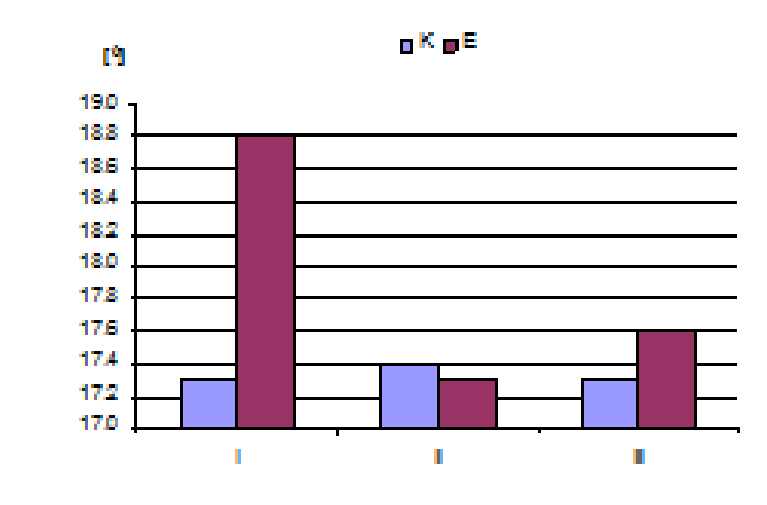

Right foot

Fig. 11. Gamma angle (boys)

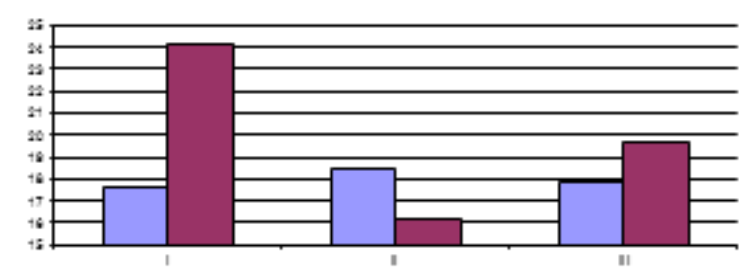

Left foot

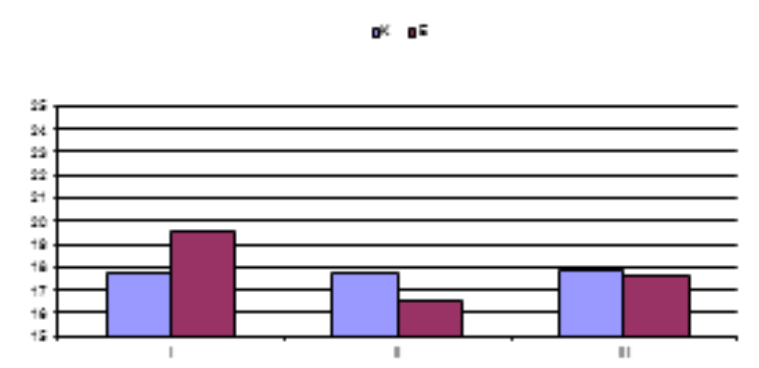

Right foot

Fig. 12. Gamma angle (girls)

In most comparisons basketball players are characterized by higher values of the gamma angle. Only in the second age class for the right foot, the above mentioned feature reaches a slightly higher level in the control group. In the youngest and the oldest age class the discussed feature reaches a higher higher value in female basketball players. In the other comparisons it achieves slightly higher values among the girls not practicing sport.

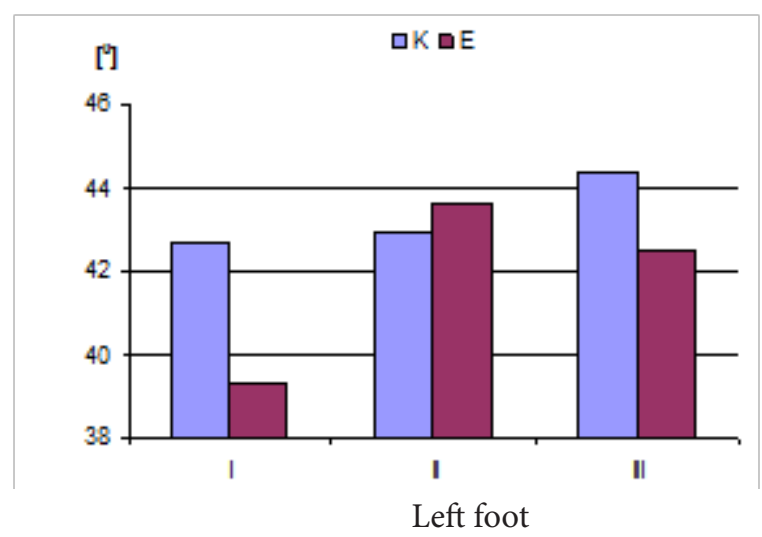

Fig. 13. Clark's angle (boys)

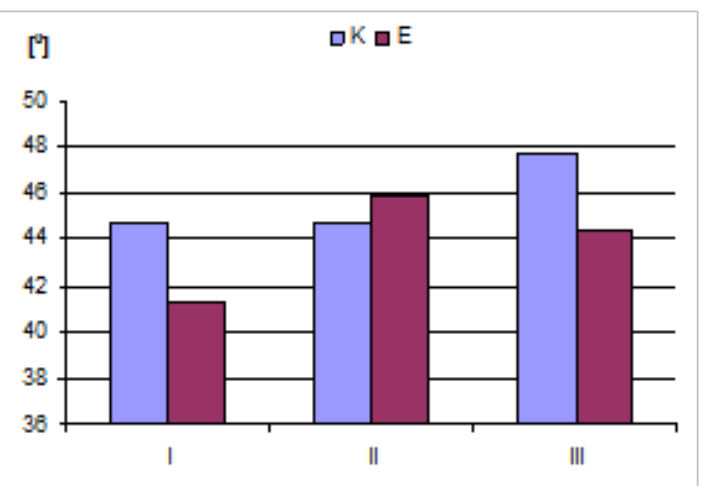

Right foot 


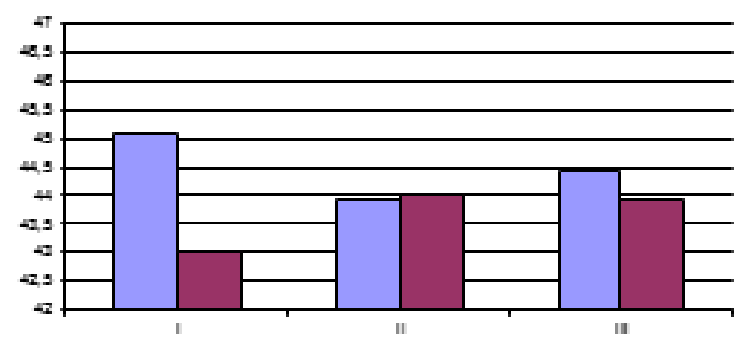

Left foot

Fig. 14. Clark’s angle (grils)

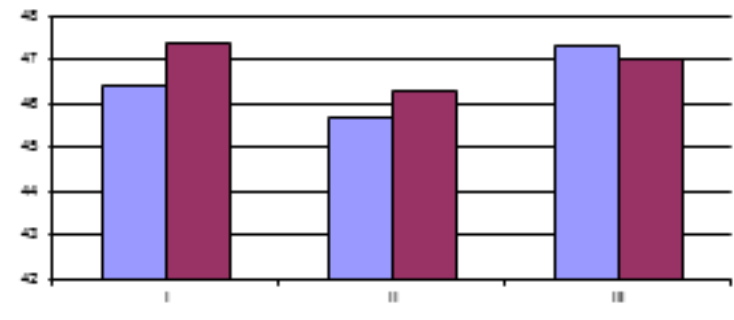

Right foot

The values of Clark's angle, describing the longitudinal arching of the foot, show greater variation between groups compared to the previously discussed angular features. Statistically significant differences in favor of the examined people in the control group were observed in the first age class and in the third one, but only for the right foot. Small differences were observed between the groups of girls.

\section{Results morphological characteristics of feet}

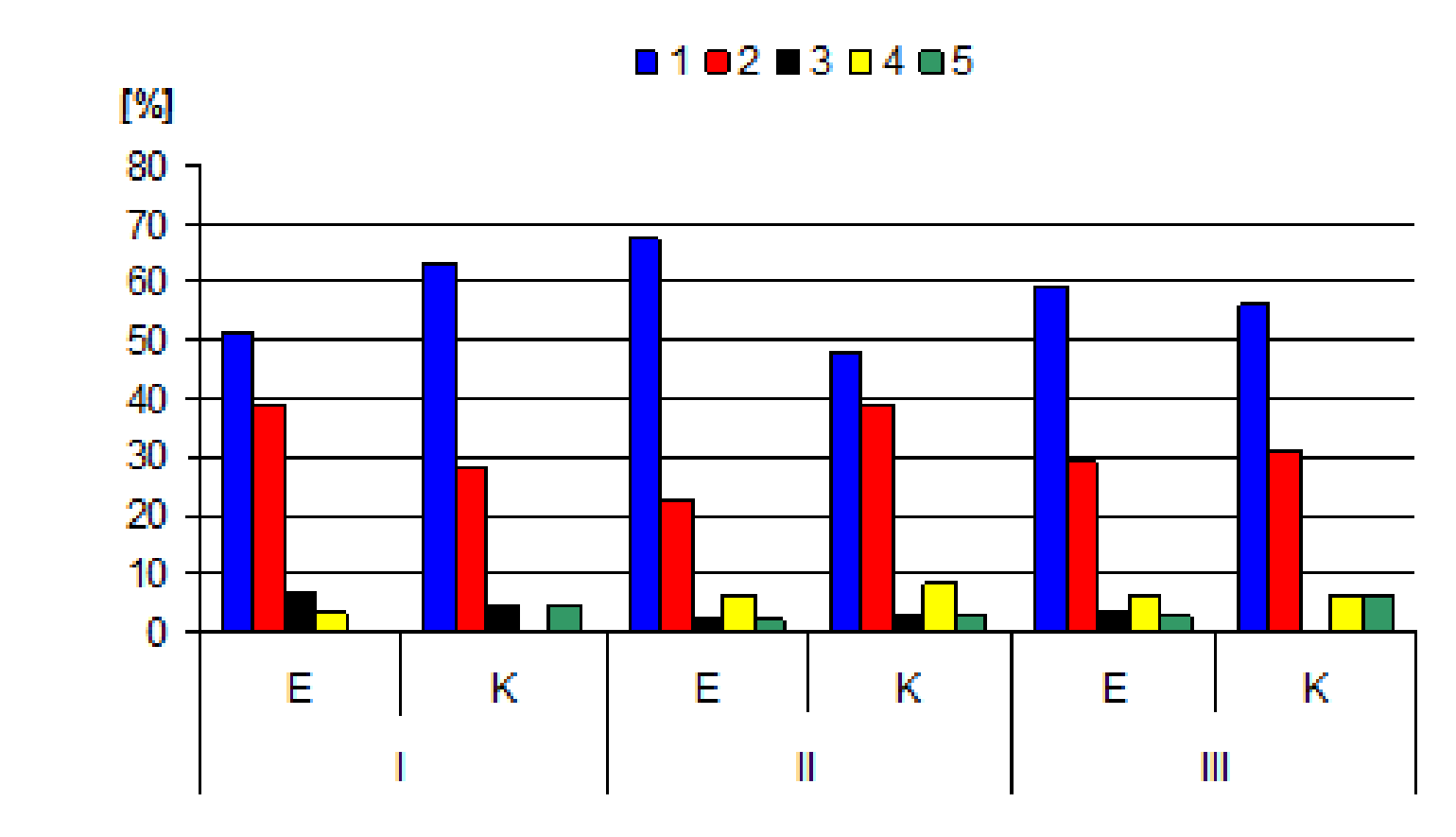

Fig.15. The incidence of foot types (L) in boys in age groups

(1 - regular , 2 - pronated, 3 - flat , 4 - high arch , 5 - excessive high arch) 
The analysis conducted separately for each age class showed that in both groups the highest turnout characterized the regular types: pronated and regular. Regular feet, defined by the range of Clarke's angle, represent the highest percentage (approx. 50\%) in all studied age classes. The incidence of abnormal foot does not exceed $10 \%$ of the total.

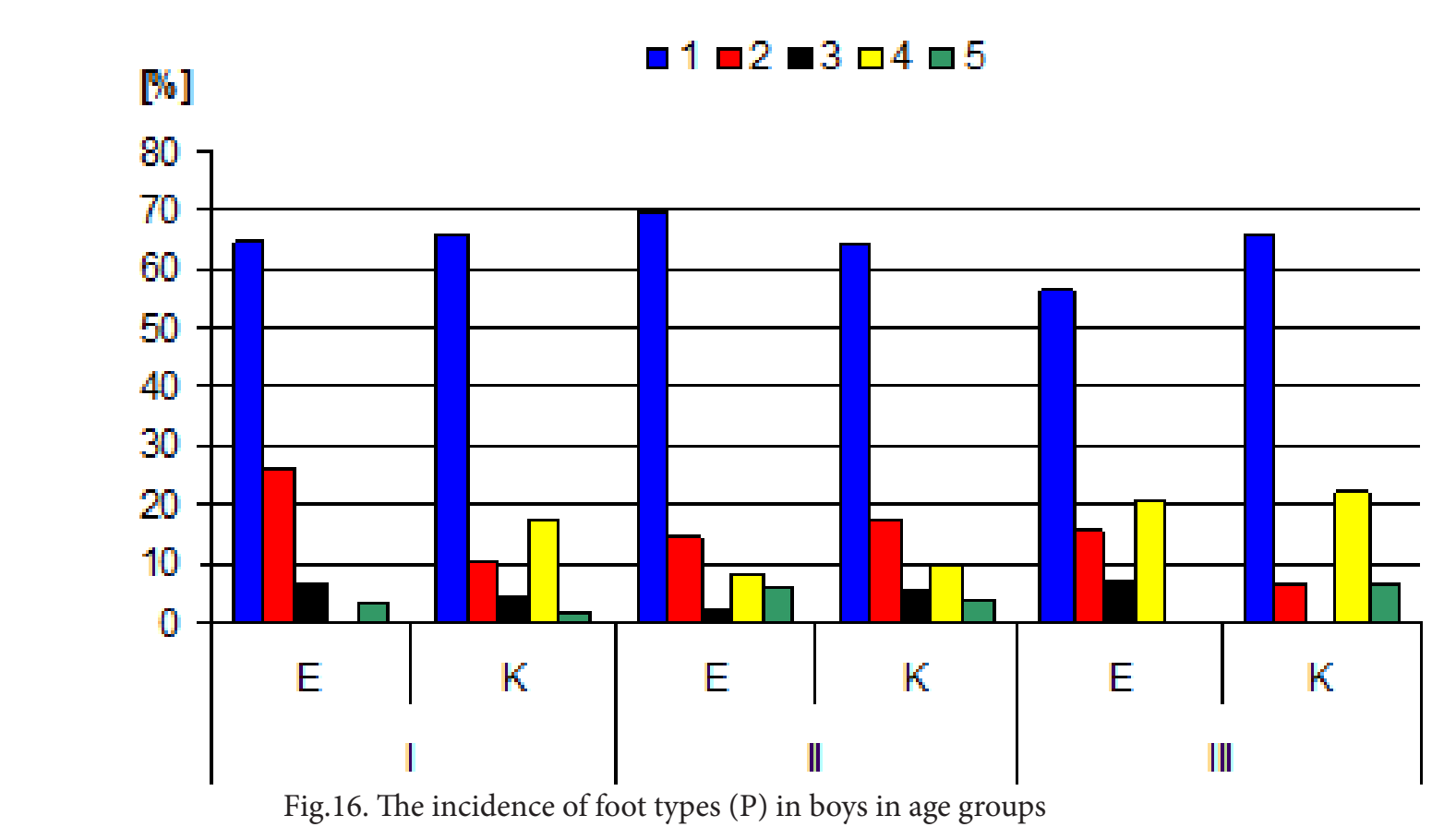
(1 - regular , 2 - pronated, 3 - flat , 4 - high arch , 5 - excessive high arch)

The results of the the incidence of foot types on the right side of the body are similar to those noted for the left foot. In basketball players regular feet were the most frequent. They accounted for over $60 \%$ of all the studied types of the right foot. With age, the incidence of flat feet and arch feet increases. [4]

In the control group the percentage of normal feet was also the highest and stood at a similar level in all age classes. The incidence of the pronated foot was higher in younger age classes. At the same time occasional presence of flat feet was also recorded. Among the students not practicing sport, it was observed that the incidence of arched feet is greater than in case of sportspeople. With age also increases the incidence of the excessive arch foot. 


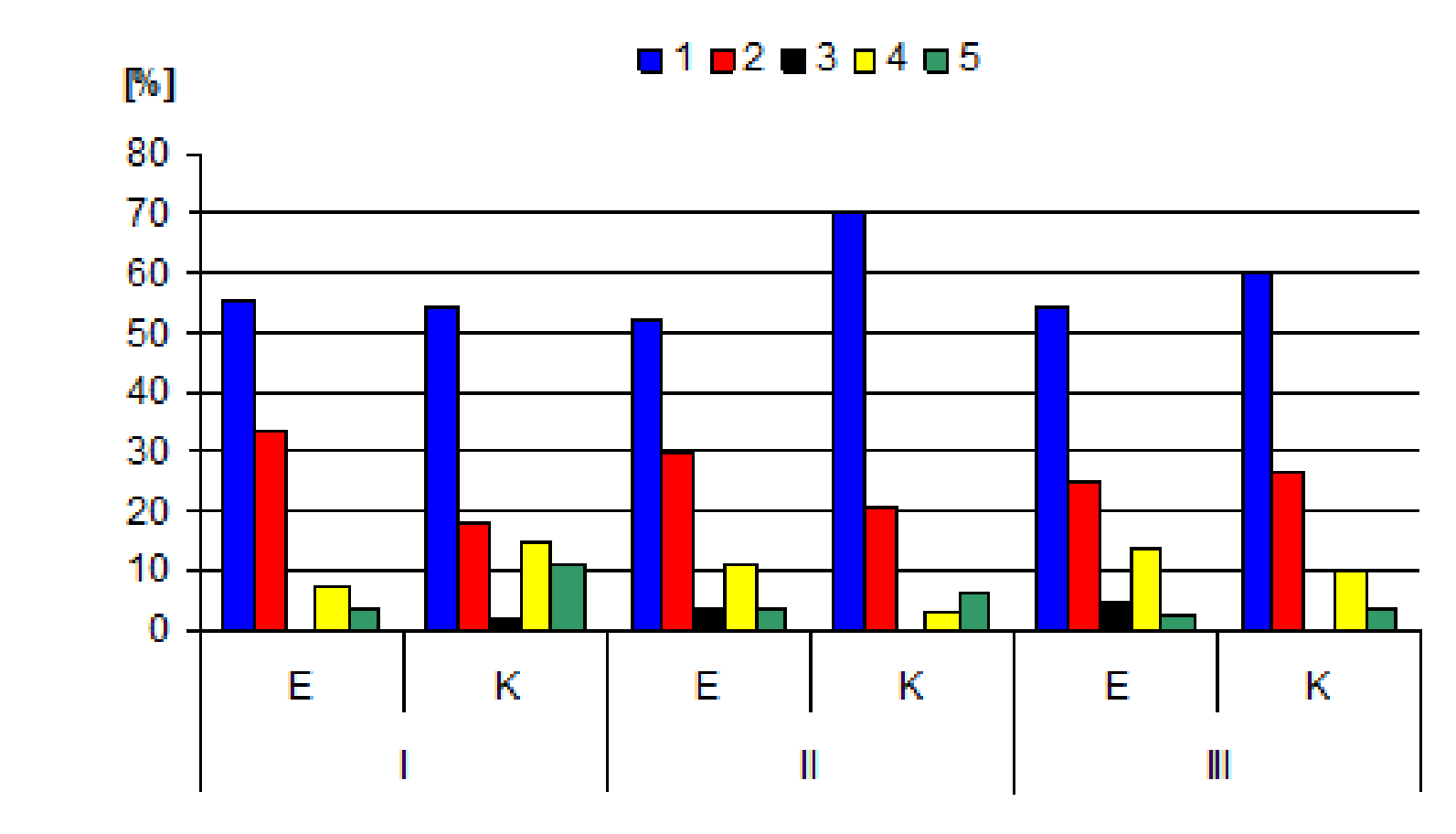

Fig.17. The incidence of foot types (L) in girls in age groups

(1 - regular , 2 - pronated, 3 - flat , 4 - high arch , 5 - excessive high arch)

The Figure 17 shows the incidence of the various types feet on the left side of the body in girls from the experimental and control groups. The analysis showed that in both basketball players and students not practicing sport, the most frequent were regular feet. With age of players increases the incidence of arch feet.

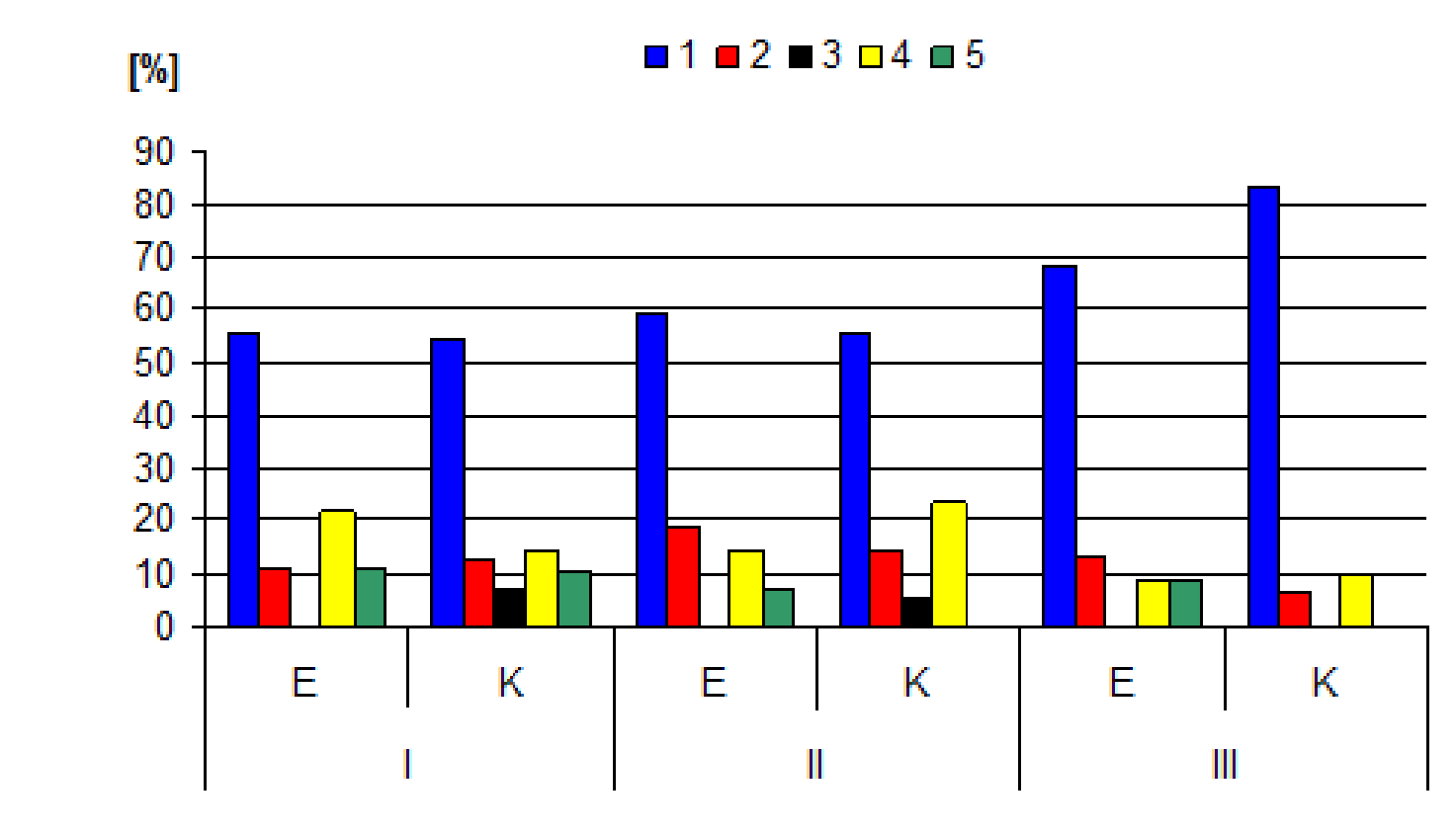

Fig.18. The incidence of foot types $(\mathrm{P})$ in girls in age groups

(1 - regular , 2 - pronated, 3 - flat , 4 - high arch , 5 - excessive high arch) 
Within the right foot in both groups there is a tendency towards gradual increase of the percentage of regular feet. There was no flat feet in female basketball players.

\section{Conclusions}

In conclusion, it can be stated that in the young people regular feet are the most common type, however both in boys and girls the percentage of the defects is slightly larger on the left side. In basketball players a slight tendency towards decreasing the incidence of regular feet with age was observed. This trend is more clearly visible in the case of the right foot. The occurrence of abnormal feet in turn, is increasing and is associated primarily with an increase in the incidence of arch and excessive arch feet. [5]

In the female basketball players the incidence of regular feet on the left side of the body is reduced with age, while on the right side the trend is different. The occurrence of abnormal feet increases in the consecutive age classes as a result of growth in the number of flat feet and arch feet. On the right side of the body the abnormal feet are the most common among the youngest players. With age there was a tendency towards decrease of the incidence of flat feet and arch feet.

Under the influence of sports training an increased incidence of adverse changes characterizing the feet of male and female players was observed. An increased occurrence of arch feet among both genders as well as excessive arch feet among the boys and flat feet among the girls was observed.

\section{References:}

1. Śliwa W. Instrukcja obsługi podoskopu.2002.

2. Kasperczyk T. Wady postawy ciała diagnostyka i leczenie. Kraków:Kasper;1998.

3. Malinowski A, Bożiłow W. Podstawy antropometrii: metody, techniki, normy. Warszawa-Łódź: PWN; 1997.
4. Malinowski A. Auksologia. Rozwój człowieka w ujęciu biomedycznym. Zielona Góra: Uniwersytet Zielonogórski; 2004.

5.Palczewska I, Niedźwiecka Z. (1999) Siatki centylowe do oceny rozwoju somatycznego dzieci i młodzieży. Warszawa: IMiDZ; 1999.

\section{Correspondence address:}

Przyszlak Agnieszka

Faculty of Physical Education, University of Rzeszów Towarnickiego 3, 35-959 Rzeszów, Poland 